\title{
Mathematical toolbox and its application in the development of laboratory scale vertical axis wind turbine
}

\begin{abstract}
Wind turbine works with the principle of extracting energy from the wind to generate electricity. The power generated is directly proportional to the wind speed available. There are two major types of wind turbine design, namely the horizontal and vertical axis wind turbine depending on the orientation of the turbine rotor and its generator. This paper deals with the design of vertical turbine due to its advantage of operating at a low wind speed over that of horizontal turbine. The analysis of change in the parameters of a vertical axis wind turbine is investigated to get the optimized way in which the rotor of the turbine is to be designed. This is done through modelling and simulation of the turbine using various parameters in the MATLAB/SIMULINK environment. A graphical user interface is created for a generic model of vertical axis wind turbine that is used to determine its parameters.
\end{abstract}

Keyword: Vertical axis; SIMULINK; Mechanical power; Wind turbine 